Cahiers $d u$ MONDE RUSSE

\section{Cahiers du monde russe}

Russie - Empire russe - Union soviétique et États indépendants

$50 / 2-3 \mid 2009$

L'Europe orientale, 1650-1730. Crises, conflits et renouveau

\title{
Bolshevik Sexual ForensicDan HEALEY
}

, DeKalb, IL : Northern Illinois University Press, 2009, 252 p.

\section{Grégory Dufaud}

\section{(2) OpenEdition}

\section{Journals}

Édition électronique

URL : https://journals.openedition.org/monderusse/9759

DOI : $10.4000 /$ monderusse. 9759

ISSN : $1777-5388$

Éditeur

Éditions de l'EHESS

Édition imprimée

Date de publication : 15 septembre 2009

ISBN : 978-2-7132-2260-3

ISSN : $1252-6576$

Référence électronique

Grégory Dufaud, «Bolshevik Sexual ForensicDan HEALEY », Cahiers du monde russe [En ligne], 50/2-3 2009, mis en ligne le 14 janvier 2013, consulté le 03 septembre 2022. URL : http://

journals.openedition.org/monderusse/9759; DOI : https://doi.org/10.4000/monderusse.9759

Ce document a été généré automatiquement le 3 septembre 2022

Tous droits réservés 


\section{Bolshevik Sexual ForensicDan HEALEY}

, DeKalb, IL : Northern Illinois University Press, 2009, 252 p.

Grégory Dufaud

\section{Dan HEALEY, Bolshevik Sexual Forensic, Diagnosing Disorder in the Clinic and Courtroom, 1917-1939, DeKalb, IL : Northern Illinois University Press, 2009, 252 p.}

1 Après s'être intéressé à l'homosexualité en Union soviétique, Dan Healey examine le regard que portent la médecine légale et la psychiatrie des années 1920 sur la sexualité. Il s'appuie sur un dossier documentaire composé d'imprimés et d'archives provenant de Moscou, Saint-Pétersbourg et Ekaterinbourg. L'auteur a notamment exhumé 194 dossiers de justice: 66 pour Petrograd (période 1922-1924); 128 pour Sverdlovsk (années 1926-1928). Ces documents constituent toute la richesse de l'ouvrage qui montre la façon dont les médecins furent sollicités par la police et par la justice, le type d'expertises qu'ils réalisèrent et la manière dont celles-ci furent utilisées lors des procès.

2 Le livre, composé de cinq chapitres, s'interroge sur l'idée de révolution sexuelle. Il débute en traitant de l'institutionnalisation de la médecine légale dans les premières années du régime soviétique. Jadis sous l'autorité de la police, celle-ci fut placée sous la tutelle du commissariat à la Santé avant que les experts médicaux ne fussent érigés en « juges scientifiques des faits » en février 1919. À partir de 1922, leur activité reposa sur le nouveau Code pénal dont plusieurs articles concernaient les délits sexuels: les articles 166, 167, 168 envisageaient la sexualité avec une personne qui n'était pas « sexuellement mature »; l'article 169 se penchait sur le viol. À bien des égards, les bolcheviks satisfirent les revendications que la médecine légale formulait depuis longtemps. Toutefois, les ressources financières et humaines ne furent jamais suffisantes pour pourvoir à ses besoins.

3 Le deuxième chapitre se penche sur la notion de «maturité sexuelle " (polovaja zrelost') venue remplacer celle d'âge légal qui imposait un même standard à des individus 
physiologiquement différents. Dans les faits, cette notion souleva une foule de complications qui conduisirent les médecins à envisager à la fois le développement physique et les caractéristiques sexuelles. La femme fut de fait souvent réduite à la fonction reproductive.

Les viols sont l'objet de la section suivante. Leur nombre dans la RSFSR, d'après les données de la police et de la Direction centrale des statistiques, fut de 9521 en 1925 et de 8198 lors des neuf premiers mois de 1926. Dans les cas d'agression sexuelle, seule la victime, le plus souvent féminine, était auscultée. Se concentrant sur les dommages physiques, les médecins portaient leur investigation sur le corps, en particulier les organes sexuels, au détriment des aspects psychologiques. Cette démarche, qui relevait d'un souci d'objectivité, présentait également, pour la police et la justice, l'avantage de l'intelligibilité et de la clarté.

5 L'auteur s'intéresse dans le quatrième chapitre à la psychiatrie légale, que les bolcheviks reconnurent et institutionnalisèrent. L'établissement le plus important, qui s'illustra plus tard par son rôle dans les répressions, était l'institut Serbskij de Moscou, fondé en 1921. Dans les cas de crimes sexuels, les psychiatres n'étaient que rarement sollicités et, dans ce cas, travaillaient de concert avec d'autres médecins. Peu de criminels, y compris les psychopathes, étaient jugés irresponsables: la notion d'irresponsabilité était entendue dans un sens très étroit, réservée aux malades les plus graves. La justice devait alors se prononcer sur le sort des inculpés et se montrait indulgente avec les amis de classe ou les membres du parti.

6 Enfin, la dernière section est consacrée à l'hermaphrodisme. En 1925, 54 examens furent effectués en Russie pour déterminer le sexe d'individus. En 1926, un acte fut émis par le commissariat aux Affaires intérieures qui octroyait la possibilité de modifier le sexe dans les documents d'état civil à l'appui d'un avis médical, conférant ainsi aux médecins une autorité nouvelle sur cette question. Pour ces derniers, l'hermaphrodisme était un problème social, du fait du stigmate qui frappait les individus à l'identité sexuelle ambivalente. La priorité était de les réintégrer dans le corps social. Les médecins pratiquèrent des " opérations de complicité ", qui, en retour, rendirent caduques le texte de 1926.

7 À travers ces différents chapitres qui fonctionnent comme une série d'éclairages successifs, cet ouvrage propose un récit passionnant de la médicalisation de la sexualité. Dan Healey précise les étapes de l'institutionnalisation de la médecine légale avant d'évoquer les pratiques et le discours des praticiens grâce à une analyse précise et détaillée des expertises dont il dispose. Il souligne le rôle du genre et de la classe comme le refus des médecins de sonder la psyché des individus et, partant, les formes de conservatisme d'une profession dont l'indépendance vis-à-vis de la police et de la justice était en réalité limitée, ne serait-ce que par la nécessité de se faire comprendre. Dans les années 1930, comme l'auteur l'indique dans la conclusion, son autonomie fut restreinte et ses conditions de travail changèrent. Elle n'en continua pas moins à occuper un rôle essentiel dans l'évaluation des troubles sexuels. 